\title{
UNIVERSIDADES LOCALES: EJEMPLOS DE MARCOS DE INTERACCIÓN PARA EL ESTABLECIMIENTO CONTENCIOSO DE CONVENCIONES CULTURALES
}

\author{
Luis Arturo Ávila Meléndez*
}

\section{RESUMEN}

Utilizo los avances de una investigación sobre el desarrollo de dos universidades locales para mostrar que la negociación del sentido de los símbolos se orienta por condiciones históricas y relaciones de poder particulares. Las universidades locales, en tanto que marcos de interacción concretos, emergen dentro de procesos de regionalidad en los que existen y se transforman grupos socioculturales en relaciones asimétricas contendiendo por el establecimiento de convenciones que favorecen que una forma de interpretar la realidad sea considerada 'natural'. Trato de hacer así un aporte al debate general sobre el origen de la referencia simbólica desde el realismo histórico.

Palabras clave: educación superior, convenciones socio culturales, negociación de sentido.

\section{RÉSUMÉ}

J'emploie l'analyse du développement de deux universités locales pour montrer que la négociation du sens des symboles est orientée par des conditions historiques et relations $\mathrm{du}$ pouvoir particulières. Les universités locales, comme des cadres d'interaction concrets, émèrgent de procès de regionalité où il existent et se transforment des groupes socioculturels qui tiennent des rapports inégaux et se battent pour l'établissement de conventions qui rendent possible qu'une forme d'interpréter la réalité soit considérée 'naturelle'. De cette manière,

\footnotetext{
* Estudante de doctorado en Antropología Social en El Colegio de Michoacán, A.C.
} 
Educação e Filosofia, 17 (33) 139-169, jan./jun. 2003

j'essais de faire une contribution au débat général sur l'origine de la référence symbolique selon le réalisme historique.

Entrée: éducation supérieur, arrengements socioculturels, négotiation du sens.

\section{Introducción}

El objetivo de este artículo es contribuir al debate general sobre el origen de la referencia simbólica o de la producción de sentido. Para dar especificidad y concreción a mi aportación, recurriré a los avances de una investigación sobre el nacimiento y desarrollo de dos escuelas de educación superior privadas en Michoacán, México. ${ }^{1}$ Dadas las funciones (educativas) de algunas instituciones de enseñanza superior, resulta fructífero abordar dichas instituciones haciendo énfasis en las disputas, en las que ellas participan, en torno al establecimiento de convenciones socioculturales.

Dentro del debate general, me sitúo del lado de las ciencias históricas $\mathrm{y}$, en particular, del realismo histórico tal como se ha ido desarrollando en la antropología. Tomando como base el caso concreto de dos instituciones de educación superior (IES) ubicadas en ciudades distintas y contrastantes precisaré los interpretantes, ${ }^{2}$ formas contenciosas de convencionalización, que predominan en cada escuela y sugeriré las bases históricas que parecen sostenerlos. Para esto, aludiré a las tradiciones culturales o selecciones culturales que señalan vínculos peculiares con instituciones y redes de relaciones entre actores, y que parecen orientar la acción social de los actores en tanto que están inscritas en cierto grado en un amplio conjunto de prácticas culturales incorporadas por ellos (Roseberry 1989:26-28). Con el mismo fin presentaré al mismo tiempo, un poco entre líneas,

1 Investigación posible gracias al apoyo financiero del Consejo Nacional de Ciencia y Tecnología. Este artículo debe mucho a la revisión de la obra de Pierce hecha por mi asesor de Tesis, Dr. Andrew Roth.

2 Término que retomo de Pierce. 
la forma en que se apropian y enfrentan las tendencias que gradualmente han cobrado predominancia en México: La privatización (educación como mercancía) en un país donde la educación superior financiada por el estado ha sido dominante, y el giro de la especialización hacia la formación masiva de gente "versátil", con carreras técnicas, en un país no desarrollado (restringiendo la abrumante mayoría de la producción científica de punta a los países desarrollados). Todo esto se concretiza en las estrategias, acciones y discursos presentes en el surgimiento y desarrollo de ambas escuelas de educación superior, que están orientadas por tentativas de convenciones socioculturales contrastantes.

Supongo que la explicación de as especificidades de la producción cultural, de la cual forman parte los interpretantes y tradiciones culturales que serán expuestos aquí, reside en las relaciones de poder concretas en las que se hallan los actores involucrados con las escuelas, relaciones de poder que derivan de sus condiciones de posibilidades simbólicas tanto como de sus posibilidades materiales. Para precisar la regionalidad, resultado de tales relaciones de poder, que está implicada en la producción cultural y que ha engendrado a las instituciones educativas requiero identificar las particularidades de las escuelas en sí mismas y las particularidades de los campos sociales en los que han surgido. En este escrito me enfocaré básicamente al primer punto. ${ }^{3}$

Primero expondré la forma en que, desde la antropología histórica, se ha planteado el debate sobre las bases de la referencia simbólica. Luego proporcionaré un contexto mínimo de las instituciones de educación superior privadas en México y Michoacán, y una síntesis de los procesos de instauración de los dos casos concretos. En las dos secciones subsecuentes expondré un análisis parcial de la ceremonialidad, los discursos públicos y los vínculos de los fundadores con otros actores y con instituciones, derivado de la información

3 Ambos puntos son parte de la investigación que me encuentro realizando dentro del programa de doctorado en antropología social. Con base en los avances realizados hasta el momento, me permitiré hablar de dos regiones, Zamora y Zacapu, aunque en este escrito no presente la información suficiente para tal afirmación. 
obtenida a través de historias de vida, fuentes hemerográficas, entrevistas y observación participante. En esas secciones trataré de demostrar el argumento principal: que los cambios y las cristalizaciones de los significados que median la interacción social, y que definen incluso los tipos de sujetos que interactúan, están vinculados de manera fundamental a relaciones de poder concretas. Terminaré con algunas reflexiones que ayuden a comprender el valor contemporáneo de aportes como el que intento hacer, en tiempos de la "acumulación flexible" en los que los medios masivos de comunicación expanden reduccionismos y categorías sociales "como si fueran naturales" desligándolos de las relaciones asimétricas en las que se originan y presentándolos simplemente como la única opción y/o como la mejor. Desde la perspectiva cartesiana tal vez habría más esperanzas de que la razón rompiera los desequilibrios, pero la historia muestra un desenlace diferente.

\section{El debate sobre la producción de sentido}

Desde una perspectiva de la historia cultural, la producción cultural de sentido no se deriva de una especie de mentalise, estructuras universales de pensamiento o dispositivos especializados programados genéticamente para producir "discursos" con base en "gramáticas" o códigos universales. Por el contrario, la producción de sentido es entendida como resultado de una capacidad general de referencia simbólica del ser humano que se despliega dentro de condiciones sociales particulares. De ahí se deriva su empeño por analizar procesos sociales reales en tiempo histórico y las objetivaciones ocurridas en estas secuencias temporales, por lo que es esencial un análisis de la producción cultural entendida como un proceso social material. ${ }^{4}$

4 En la actualidad el debate se plantea entre ciencia cognitiva (Pinker, Chomsky, Levi-Strauss, etc.) y ciencia histórica (Deacon, Vigostky, E. Wolf, etc.). El origen del debate puede rastrearse hasta la obra de Vico en el siglo xvIII en su crítica a la comprensión de la realidad exclusivamente por medio de una ciencia racionalista, y a favor de entender al racionalismo mismo como una producción humana de un 
Dentro de la antropología, un primer deslinde que debo hacer, y que tiene grandes consecuencias para la práctica de investigación antropológica y atraviesa una gran cantidad de obras en antropología y geografía (Roseberry 1992, Sayer 1993, Nugent 1988), es aquel que existe entre una postura que realiza un esfuerzo por situar tanto las prácticas concretas como la generación social de las conciencias (subjetividades) dentro de procesos históricos interconectados, es decir, un esfuerzo por dar cuenta del "desarrollo histórico de tipos bastante específicos de relaciones sociales" (Smith 1999: 9), en contraste con una antropología definida básicamente como una crítica cultural (Clifford y Marcus 1986). ${ }^{5}$

Al decir que la producción cultural es un proceso social material, desde la postura del realismo histórico que estoy retomando (Williams 1980, Harvey 1999: 24-25), se asume que las experiencias de interiorización y exteriorización de formas de mediación simbólica (G. Mead 1990) y la formación de la personalidad individual ocurren en un campo jerarquizado de relaciones sociales (Bakhtin 1987), y que "las ideas toman formas por sí mismas que no son directamente deducibles de hechos materiales o sociales, pero que están implicadas en la producción material y la organización social y por tanto necesitan ser comprendidas en tal contexto" (Wolf 1999: 19). De manera que las formas simbólicas se interiorizan, pero no se interiorizan igual desde posiciones distintas. Resulta clara entonces la importancia de los "campos de fuerzas" en los que ocurren determinadas prácticas e interrelaciones culturales. Para aproximarse a dichos campos de fuerza, no se requiere sólo descubrir "patrones

momento histórico (De Amorim y Neto, 2001). Más recientemente, Calvin y Bickerton (2001) realizaron una síntesis desde la biología evolutiva, retomando parte de la explicación de Deacon (1997), en la que el innatismo de las operaciones sintácticas salió favorecido y poco explicado el origen del sentido del lexicón.

5 Marcus y Clifford dudan de la posibilidad de escapar a una narrativa selectiva y totalizadora de la historia para especificar la relatividad histórica de los procesos a los que Wolf o Roseberry les suponen cierto realismo. Taussig (1989) acusa a Wolf y Mintz de reproducir la fetichización de la mercancía con sus libros mismos y por centrarse en las mercancías como objetos y no en una reflexión crítica de los mecanismos de su fetichización (ver la respuesta en Mintz y Wolf 1989). 
culturales" y mostrar su puesta en marcha sirviendo como modelo de y para la acción social (Geertz 1987), sino que es necesario especificar la formación histórica de relaciones sociales concretas (constituidas también simbólicamente) dentro de sus posibilidades materiales particulares.

Lo que hago en este artículo es describir los interpretantes que participan en el nacimiento y desarrollo de dos escuelas. Al iniciar la investigación supuse que tales intentos de convencionalización estrían "familiarizados" con, pero al mismo tiempo serían innovaciones de, tradiciones culturales sedimentadas en dos regiones distintas. Al contrastar los interpretantes en dos casos diferentes busco evidencia de que las tradiciones culturales, actualizadas dentro de redes de relaciones sociales particulares, tienen sus raíces en desarrollos históricos particulares (sedimentación en infraestructura, interiorización en disposiciones durables de las personas, legitimación en los principios de orden de diversas instituciones), y que por lo tanto señalan procesos de regionalidad ${ }^{6}$ distintos. Este planteamiento me permitió buscar indicios de fronteras culturales existentes entre dos lugares, la ciudad de Zamora y la ciudad de Zacapu. Las redes de relaciones sociales así especificadas, relevantes al desarrollo de cada institución, ubican a los actores sociales concretos dentro de un campo social internamente diferenciado (relaciones de poder concretas). De forma que los interpretantes, más allá de su análisis en términos puramente semánticos o estructurales, quedan ligados ineludiblemente a particularidades culturales materiales en las que se desarrollan. Como dije, las formas simbólicas se interiorizan y se vuelven convencionales, pero no se interiorizan igual ni tienen las mismas posibilidades de convencionalizarse desde posiciones distintas.

Por interpretante entiendo-siguiendo a Pierce (apud. Wolf 1999: 54) - un arreglo que puede establecer el sentido de los signos (producciones culturales) en un área social particular, un aparato con una estructura y función similar a una ideología, entendida ésta

${ }^{6}$ Siguiendo a Van Young (1992: 2), regionalidad corresponde a la calidad de ser una región, mientras que regionalismo es una identificación cultural, política y sentimental que amplios grupos de gente desarrollan a lo largo del tiempo con ciertos espacios geográficos. 
como selecciones y codificaciones de principios culturales "desarrollados para garantizar o para manifestar poder" (Wolf 1999: 4). Un interpretante es un signo (una referencia simbólica) que establece una relación compleja, arbitraria pero con posibilidades de convertirse en convencional, entre otros signos y sus referentes en un área social particular. Pierce enfrenta así la cuestión de la "arbitrariedad" de la relación entre signos y sus referentes: Una relación, de las muchas posibles, logra ser establecida como convencional. Si este arreglo de sentido se vuelve convencional, entonces los actores sociales cuentan con un interpretante de la realidad, y pueden referirse a esta visión del mundo como un "descubrimiento de la realidad", en palabras de uno de los personajes de este estudio. ${ }^{7}$ Pero el que se vuelva convencional depende de las posibilidades materiales y simbólicas de los actores concretos que promueven al interpretante. En el articulo analizo la participación de un interpretante dentro de cada desarrollo institucional y las redes de relaciones de los actores involucrados en ellos para tener una idea del posible establecimiento de estos interpretantes como una convencionalización.

Dado que las relaciones sociales dependen de " "la organización de la diversidad» a través de la interacción recíproca" debemos tratar de comprender "cómo trabaja el poder en las relaciones sociales para generar coherencia a partir de las formas culturales y lingüisticas...debemos tratar de identificar los medios instrumentales, organizacionales, o ideológicos que mantienen la costumbre o aseguran la búsqueda de coherencia...podríamos tratar de identificar los agentes sociales que instalan y defienden las instituciones y que organizan la coherencia, y para quiénes y contra quiénes lo hacen" (Wolf 1999: 66-67). Aquí es donde encuentra un lugar específico el objeto de interés de mi investigación, pues considero que las dos instituciones educativas locales son marcos de interacción cuya creación y funcionamiento puede mostrar parte de esta dinámica en que el poder organiza la diversidad dentro de espacios regionales.

7 De modo que las selecciones en las que se da primacía a unos valores y elementos culturales sobre otros y que logran establecer convenciones sobre el orden social y 'naturalizarlo' transitoriamente son susceptibles de ser usadas en relaciones de poder (Lomnitz 1995: 52 ss.). 
Educação e Filosofia, 17 (33) 139-169, jan./jun. 2003

Instituciones privadas de enseñanza superior: Dos casos contrastantes

Las instituciones privadas de educación superior en México comenzaron a atender a una proporción cada vez mayor de la matrícula total principalmente a partir de la década de 1980. En el ciclo 2000-2001, una tercera parte de los alumnos de educación superior asistieron a una institución privada (ANUIES 2001: 5). A lo largo del tiempo se ha desarrollado una oferta heterogénea desde el punto de vista de los acuerdos jurídicos que otorgan a cada institución privada su autonomía o supeditación a alguna autoridad (Mendoza 1998: 331). Pero hasta muy recientemente la oferta de carreras ha sido redundante y poco coordinada. ${ }^{8}$ Más que una oferta innovadora, las universidades públicas y privadas habían ofrecido las carreras tradicionalmente más demandadas por los egresados del nivel bachillerato, y aún en gran medida sigue siendo así.

En cuanto al desarrollo de las escuelas privadas de educación superior, se han identificado dos etapas en las que se presentaban contextos diferentes y en las que surgieron instituciones con características también contrastantes. A lo largo de la primera etapa predominó la formación de universidades de élite, apoyadas ya sea por empresarios ya sea por la iglesia católica desde 1935. En la segunda etapa, a partir de los años 80 , aunque siguieron creciendo las universidades de élite, destacó el surgimiento de un gran número de pequeñas instituciones privadas de absorción de las demandas estudiantiles, "que concentran su oferta de servicios docentes en torno a un núcleo de carreras de alta demanda y bajos costos de producción" y cuentan con una matrícula generalmente inferior a los 300 alumnos (Mendoza 1998: 331-338). El número de este tipo de escuelas pasó de 77 en 1980 a 301 en 1995 (Kent y Ramírez 1998: 321).

En 1970 más de la mitad de las escuelas de educación superior se concentraba en la ciudad de México (ídem.: 310), muestra de que territorialmente ha habido una diferenciación marcada. Como parte

8 Lo que algunos han llamado "multiplicación sin innovación" (Kent y Ramírez 1998: 312). 
del fenómeno de crecimiento del sistema de educación superior en general, fue gradual la expansión de la educación superior privada hacia los estados. ${ }^{9}$ Esto ocurrió de manera general siguiendo las jerarquías entre las localidades, precediendo las capitales de los estados a las ciudades menores (medianas y pequeñas). En Michoacán, persiste la centralización de servicios tal como se muestra en la siguiente tabla:

\begin{tabular}{|l|c|c|c|}
\hline \multicolumn{4}{|c|}{ Distribución del porcentaje de la matrícula de IES en las ciudades de Michoacán } \\
\hline \multicolumn{1}{|c|}{ Ciudad } & $\begin{array}{c}\text { \% de la matrícula } \\
\text { total de las IES }\end{array}$ & $\begin{array}{c}\text { \% de la matrícula } \\
\text { de IES públicas }\end{array}$ & $\begin{array}{c}\text { \% de la } \\
\text { matrícula de } \\
\text { IES privadas }\end{array}$ \\
\hline Morelia, capital del estado & 80.8 & 86 & 47.8 \\
\hline $\begin{array}{l}\text { Uruapan, segunda ciudad por su } \\
\text { tamaño }\end{array}$ & 4.4 & 0.4 & 28.8 \\
\hline En otras ciudades & 14.8 & 13.6 & 23.4 \\
\hline Fuente: Estadísticas de Educación Superior, SEP, 2001. & & \\
\hline
\end{tabular}

Las instituciones privadas de educación superior en el estado fueron fundadas a partir de los años 80 , con excepción de la Universidad Don Vasco de Uruapan que inició en 1964, y a inicios del ciclo 2000-2001 la participación relativa de la matrícula de educación privada era $14 \%$ (ANUIES 2001). La expansión de la oferta de educación superior pública se ha realizado en los últimos diez años mediante la fundación de una universidad tecnológica con carreras cortas y varios institutos tecnológicos.

Las instituciones abordadas aquí son de pequeña magnitud y en buena medida de absorción de demandas estudiantiles. Sin embargo, cobran valor por mostrar de forma concreta una frontera cultural en el espacio socialmente constituido. Por otra parte, entre los años 1960-1980 crecieron considerablemente los grupos sociales de comerciantes, profesionistas y la burocracia, cuyos miembros han sido captados precisamente por estas instituciones surgidas a principios de los ochenta que sin embargo, al menos en uno de los dos casos está vigilada por otro tipo de actores (empresarios mayores y gente vinculada a la iglesia). Tal vez en el periodo 1980-2003 no ha

9 En la actualidad hay una mayor proporción de escuelas privadas de educación superior en Nuevo León, Estado de México, Puebla, Guanajuato y Jalisco. 
surgido un nuevo tipo de sujeto antropológico en estas regiones pero en este tiempo algunos ya existentes se han vuelto predominantes e imposibles de soslayar, por lo que es importante estudiar el surgimiento de nuevos marcos de interacción que los involucran.

La ciudad de Zamora, con 122,881 habitantes (INEGI 2001), alberga a la Universidad de Zamora. La agroindustria de exportación y el comercio de bienes básicos de consumo son las actividades económicas predominantes (Verduzco 1992). El nacimiento y desarrollo de la Universidad de Zamora inició en 1984 con el patronato Fomento de Estudios Superiores del Valle de Zamora Asociación Civil (FESVAZAC), que apoyó la instalación, concretada hasta 1987, de una sucursal de la Universidad del Valle de Atemajac (UNIVA) originaria de Guadalajara y fundada a su vez por el arzobispado con sede en dicha ciudad. FESAZAC fundó, en 1992, el Instituto de Estudios Universitarios del Valle de Zamora, IVAZA, y posteriormente dejó la misión en manos de la Asociación Civil Instituto de Estudios Universitarios del Valle de Zamora, que logró la autorización de la Secretaría de Educación Pública (SEP) para el cambio de nombre en 1998, y actualmente es propietaria de la "Universidad de Zamora". En el año 2002 contaba con las carreras de derecho, contaduría pública, trabajo social, psicología y ciencias de la comunicación con reconocimiento de validez oficial por parte de la SEP federal. Es de sostenimiento particular y aunque no forma parte institucionalmente de la Iglesia católica hace pública profesión de su fe cristiana, católica. No obstante que el número de alumnos que asiste a ella es limitado (alrededor de 300), ofrece servicio a un área extensa que abarca 15 municipios. A ella asisten estudiantes de clase media, de acuerdo con el patrón de residencia, la ocupación de los padres y la proporción de alumnos que trabajan. ${ }^{10}$

En Zamora, la apertura de cinco instituciones de bachillerato entre 1987 y 1996, el éxito de UNIVA, y la apertura de tres centros de educación superior con carreras del mismo tipo entre 1997 y 2003 -el Centro de Estudios Superiores de Zamora, el Centro de estudios UNIVER y Centro de estudios superiores Primero de mayo- muestran

10 Información obtenida mediante una encuesta aplicada a $68 \%$ de los alumnos inscritos en el ciclo escolar 2000-2001. 
que el proceso de institucionalización de la educación superior en dicha ciudad está en concordancia con un proceso más amplio de privatización de la educación superior en México. Particularmente, forma parte del crecimiento del sector denominado de absorción de la demanda.

La ciudad de Zacapu, que aloja al Centro Universitario del Valle de Zacapu, alcanzó el rango de ciudad a raíz de la instalación de la planta industrial de una compañía transnacional en 1946, Celanese, dedicada a la producción de fibras sintéticas (Mummert 1994). En décadas posteriores el auge industrial inicial decayó pero permitió que se desarrollara una dinámica poblacional que demanda todo tipo de servicios y del comercio en una pequeña zona que comprende el municipio de Zacapu y algunas localidades de tres municipios vecinos. Actualmente la habitan poco más de 49,000 personas (INEGI 2001). El Centro Universitario del Valle de Zacapu (CUVZ) inició sus labores de enseñanza en 1984 y desde entonces a la fecha atiende a jóvenes mayoritariamente del municipio de Zacapu para formarlos como ingenieros industriales o licenciados en planificación agropecuaria dentro del área administrativa. Los reconocimientos de sus programas y del nombre de la institución le fueron otorgados por la Secretaría de Educación en el Estado de Michoacán en 1991. La Maestra en Ciencias, María Elena Sosa, originaria de Zacapu, junto con la profesora Amada Flores desde un inicio han diseñado y puesto en marcha este centro sin ningún apoyo regular del gobierno. El CUVZ es la única opción de nivel superior en esta ciudad, lo cual señala que no ha sido un lugar atractivo para las escuelas privadas con presencia en el estado. ${ }^{11}$

Los contrastes entre ambas instituciones, que desarrollaré en la siguiente sección, introducen el problema de cómo la creación de una institución educativa local es constitutiva a los intercambios e interacciones de los actores involucrados en redes de relaciones sociales previas y actuales con alcances en un espacio regional. En efecto, en

${ }^{11}$ En enero de 2000 se anunciaba apenas la instalación de un centro de la Universidad Autónoma de Guadalajara, institución privada, dedicado a formar "profesionales asociados" (carreras de dos años) pero en 2003 aún no se concretaba (www.uag.edu.mx, julio 2003). 
los estudios históricos y etnográficos de Zamora y Zacapu encuentro evidencias de dos configuraciones sociales contrastantes que también me llevan a preguntar respecto a cómo las redes de relaciones sociales asociadas a cada proyecto educativo local están conteniendo particularidades de la dinámica cultural regional y a la vez están formando parte de un cambio de amplitud nacional. ${ }^{12}$ En este artículo me limitaré a desarrollar las prácticas de ceremoniosas, los discursos públicos y la vinculación institucional de los personajes centrales de cada escuela.

Ubicación de Zamora y Zacapu

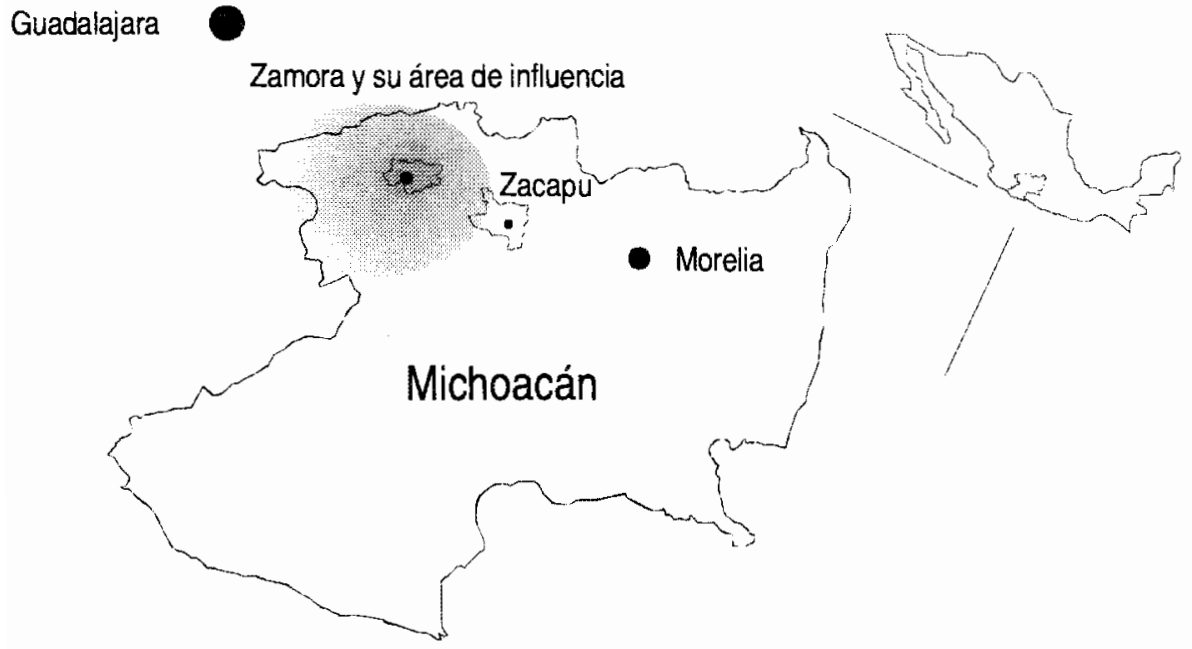

12 Por ejemplo, en el caso de Zamora, fue un centro de organizaciones sociales católicas ligadas al surgimiento de lo que se conoce como "catolicismo social" en la primera década del siglo xx (Ceballos 1991: 354 ss.). Esta base organizativa estaría ligada posteriormente a la fuerza que el movimiento cristero tuvo en Zamora y en un buen número de localidades de 15 municipios cercanos entre 1926 y 1929 (Purnell 1999: 91-92). Aunque el Partido Acción Nacional (PAN) ha tenido una cierta presencia desde 1940 en Zamora sólo hasta 1983 un 'nuevo PAN' (Almada 2001: 132) opuso de manera efectiva una unidad zamorana frente a Morelia como un centro político externo y ganó la presidencia municipal. En el conflicto derivado de estas elecciones el clero apoyó a este partido que mantiene en su discurso los valores de la familia, la iglesia y la propiedad privada (Zepeda 1988: 148). Desde entonces, el PAN en Zamora ha ganado 6 veces la alcaldía con una sola interrupción. 


\section{Redes sociales e institucionales}

A lo largo de la historia reciente de México, en ambas regiones han sido establecidas instituciones vinculadas de forma más o menos directa a proyectos políticos en un momento determinado, y a tradiciones objetivadas e incorporadas (con disputas) en prácticas cotidianas y en las personas mismas. Las dos escuelas de mi investigación son de alguna forma una cristalización diferenciada de estas trayectorias político-culturales ligadas a los cambios en la relación entre Iglesia católica y Estado y a la conformación del estado revolucionario.

El proyecto de la Universidad de Zamora ha pasado por una transición y en cierto grado una ruptura dentro del núcleo de personas que lo impulsaron originalmente. Pero en ambos momentos dentro del Patronato FESVAZAC y dentro de la Asociación civil IVAZA apoyada por la más reciente Asociación Pro-Universidad de Zamora, han estado involucrados ciudadanos que continúan con sus actividades empresariales o profesionales además de impulsar la iniciativa educativa. Esto me ha llevado a redes más amplias que exceden los espacios propiamente escolares.

En el primer patronato que apoyó la llegada de la UNIVA (1984-1992) participó el Obispo de la Diócesis de Zamora. Su apoyo fue decisivo en tanto que constituyó un símbolo de confianza que permitió a la ciudadanía no dudar de la legitimidad y honestidad del Patronato y así hacer sus aportes económicos. Las primeras reuniones

La movilización hecha en 1986 contra la ley estatal de educación (Hernández 1999: 213 ss.), muestra la capacidad de convocatoria de la diócesis de Zamora a través de sus planteles educativos: diez mil personas de la diócesis participaron en una de las marchas. Por su parte, el municipio de Zacapu, desde 1909 hasta 1937, jugó un papel activo importante a favor del movimiento agrarista (Purnell 1999: 66, $111-$ 112, Friederich 1981: 79). Un cambio estructural ocurrió en 1945 con el establecimiento de un enclave industrial en Zacapu, localidad rural con recursos hidrológicos, transformó radicalmente el desenvolvimiento de la población (Mummert 1994). En las últimas décadas, la historia de formación del sindicato, la fuerza del movimiento magisterial y la orientación de algunas administraciones municipales -en particular de algunas de las cuatro ocasiones en que la administración política ha estado en manos del PRD - muestran cierta relevancia de los valores del normalismo magisterial (la escuela popular y comunitaria) y de las comunidades rurales del municipio. 
que llevaron a la formación de FESVAZAC se realizaron en el Instituto Cázares, perteneciente a la diócesis y dedicado a la formación de laicos católicos. La diócesis de Zamora, caracterizada por el dominio de la jerarquía eclesiástica sobre la religiosidad popular, ha preferido contar con un organismo que asegure la vigilancia de la formación de laicos, en parte por la amenaza que a sus ojos fueron algunos grupos carismáticos cuyos principios parecían atentar contra la autoridad clerical establecida (Tapia 1998, Hernández 1999). Uno de los sacerdotes que asistieron a las primeras reuniones y que sigue formando parte de la directiva de la actual Universidad de Zamora se doctoró en Roma, es escritor de relatos sobre la vida regional, y en 2000 era párroco de Jiquilpan, ciudad próxima a Zamora. Desciende de una familia de hacendados y empresarios zamoranos, antigua élite que decayó con la Reforma agraria en los años treinta.

Entre otros, participaron dos miembros de una familia de laicos católicos que tiene vínculos familiares cercanos con el Presidente Fox y cuyo patriarca es originario de Cotija, municipio cercano a Zamora donde se fundó y ha sido la base de la congregación de los Legionarios de Cristo que fundaron la Universidad Anahuac, con sede en la ciudad de México. ${ }^{13}$ Algunos miembros de la familia han participado en la prelatura personal del Opus Dei que, como muchos otros organismos católicos, dedica gran parte de su energía a la acción educativa. Por su parte, el padre de esta familia ha colaborado con la formación de la Escuela de enfermería de Zamora, en los años sesenta, además de participar en la llegada de la UNIVA y permanecer cerca de la Universidad de Zamora.

Tras un desacuerdo respecto a la continuación del proyecto, en 1992, FESVAZAC se separó de la UNIVA y prosiguió su tarea de fundar una universidad originaria de Zamora echando a andar el Instituto de Estudios Universitarios del Valle de Zamora, IVAZA en

\footnotetext{
${ }^{13}$ En 2003 se publicó un convenio entre la Comunidad valenciana, el Gobierno federal y el Gobierno estatal para fundar la Universidad de Artes y Oficios en Cotija con una inversión total de 84 millones de pesos en un terreno donado por los Legionarios. Ante la posibilidad de que los Legionarios la dirijan, el gobierno del estado podría retractarse del apoyo comprometido (Proceso 1343, 28 julio 2003).
} 
1993. ${ }^{14}$ En 1994, el patronato escindido y debilitado tras haber ya dado apoyo a la UNIVA dejó en manos de una nueva asociación, IVAZA, A.C., la misión. En 1993 fue nombrado rector Faustino Castro, licenciado en derecho, sacerdote en ejercicio hasta 1975, con experiencia en gerencia empresarial, escritor y participante del Opus Dei hasta 1968. Otra persona que en algún momento fue mencionada como apropiada para ocupar el cargo de rector de la futura Universidad fue el actual rector del Seminario mayor de la Diócesis de Zamora. ${ }^{15}$

En los primeros y duros años de 1993 a 1996 se reinició de la nada lo que sería más tarde la Universidad de Zamora. En el Acto académico realizado para conmemorar el egreso de la primera generación, en 1997, se hizo público un agradecimiento por un apoyo financiero a un gran empresario a escala nacional vinculado con los Legionarios de Cristo (Proceso loc. cit.). Se puede suponer, por el estado actual de la institución, que el apoyo fue puntual y modesto pero necesario por la crisis financiera por la que atravesaba IVAZA, y posible por las redes de relaciones en las que había surgido esta institución.

A pesar de las dificultades, IVAZA contaba con colegiaturas menos onerosas que UNIVA, atendía a un sector menos favorecido económicamente y cubría una demanda real de la ciudad y la región. De modo que logró consolidarse dentro de sus modestas dimensiones. Entre sus primeros alumnos, ahora egresados, se encuentran personas que asisten o han asistido a grupos de laicos católicos de Cotija, Tacámbaro, Yurécuaro y Vista Hermosa en los que también ha participado la misma directora académica de IVAZA. En 1998 obtuvo autorización para cambiar el nombre de IVAZA por el de "Universidad de Zamora". Meses antes el ayuntamiento municipal, presidido por un miembro del PAN que en sus años mozos había participado también en grupos de jóvenes católicos, declaró que

${ }^{14}$ La idea original era que la UNIVA se retirara a los cinco años de su llegada y tras haber abierto una brecha para la formación de la Universidad de Zamora, pues en 1987 el gobierno del estado se negó a ayudarlos a fundar una universidad "autónoma" de Zamora (Guía, 12 julio 1987 y entrevista con A. Verduzco, julio 1999).

${ }^{15}$ En 2000 el Seminario consiguió el reconocimiento oficial de sus programas de licenciatura de Filosofía y Teología ante la SEP a nombre del "Instituto Alfonso Méndez Plancarte". 
IVAZA era la Universidad de Zamora, fortaleciendo simbólicamente un vínculo de pertenencia entre IVAZA y una "comunidad zamorana" representada por el cabildo municipal. En 1999 se creó la Asociación Civil Pro-Universidad de Zamora cuyo presidente es hijo del dueño del grupo radiofónico más grande de México, cuya ideología católica es explícita en sus asuntos personales, pero definitivamente en los hechos también impregna en alguna forma la programación cotidiana de las radiodifusoras. ${ }^{16}$ En la ciudad de Zamora es dueño de todas las estaciones de radio cuya cobertura abarca al rededor de 25 municipios próximos. ${ }^{17}$

El Centro Universitario del Valle de Zacapu, por su parte, está inmerso en redes restringidas en torno al pequeño grupo de actores involucrados directa y casi exclusivamente con la escuela. Sus redes familiares cercanas y con profesionistas que conocieron durante su carrera laboral en las industrias han favorecido sus actividades a las que han dedicado gran parte de su tiempo durante los últimos veinte años. Durante su formación profesional, las profesoras que dirigen la escuela han formado parte del sector académico orientado a la empresa en la Facultad de Contaduría de la UNAM. En los años de expansión industrial de los años setenta el destino de los egresados de esta facultad era más diverso y prometedor que en la actualidad, de manera que, en el caso específico de las profesoras María Elena y Amada, lograron un ascenso socioeconómico notable gracias a su formación como licenciadas en contaduría. Luego de trabajar en diversas empresas transnacionales, años más tarde ingresaron de nuevo a la UNAM pero ahora para realizar estudios de posgrado en un área completamente diferente. En la Facultad de Ciencias Políticas conocieron otra "parcela" de la universidad pública desligada del

\footnotetext{
${ }^{16}$ A partir de 1998, en todo el pais se ha incrementado la transmisión de programas con contenidos religiosos, principalmente católicos, de manera que, a decir de algunos investigadores, la transmisión supuestamente "extraordinaria" de este tipo de programas se ha convertido en una práctica inconstitucional (La Jornada, 8 oct., 2000).

${ }^{17}$ Hasta el momento el apoyo de Pro-Universidad no ha sido central en el funcionamiento económico de la institución que se mantiene fundamentalmente de las colegiaturas.
} 
sector productivo y más bien encaminada a la reflexión social y política. Uno de los hermanos de la directora, profesor del mismo Centro Universitario se formó en el Instituto Politécnico Nacional ubicado en la Ciudad de México, de sostenimiento público, y más adelante se graduó en la Maestría en Pedagogía en el Instituto Michoacano de Ciencias de la Educación, antes Normal Superior de Morelia.

A una edad madura y con el gozo de haber realizado una carrera profesional plena, decidieron formar un proyecto propio que combinara el aspecto pragmático y productivo de la industria, y el aspecto crítico y reflexivo de las humanidades. Luego de dos intentos de conformar empresas en el régimen de cooperativa, emprendieron el proyecto de educación superior que aquí expongo. Decidieron desplazarse a un lugar marginal buscando beneficiar a personas con mayor desventaja económica: el municipio de origen de la profra. María Elena, Zacapu. Ubicaron además la escuela en una localidad a las orillas de la zona urbana que hasta hace poco sólo se comunicaba mediante un camino sin pavimentar. Al retornar a su tierra de origen, la maestra María Elena en cierta forma recuperó el nombre de su familia (capital de relaciones sociales): el trabajo sindical de su tío, como fundador del Sindicato de Celanese conocido por un buen número de pobladores, y algunos nexos de su padre con gente de localidades rurales les fueron de utilidad al solicitar apoyo de las organizaciones campesinas al iniciar su labor docente.

$\mathrm{Al}$ insertarse en la zona también ingresaron a la Universidad Pedagógica Nacional, con la idea de difundir su pensamiento crítico entre el magisterio. La participación de las directoras como profesoras de la UPN y necesariamente bajo la autoridad del Sindicato Nacional de Trabajadores de la Educación, repercutió a su vez en sus vidas pues, aunque no comulguen con algunas ideas o posturas de los dirigentes sindicales, han debido participar de la vivencia de movilización del magisterio michoacano, experiencias que incluyen marchas, plantones y compañerismo normalista. En un estudio sobre el movimiento magisterial a finales de los años ochenta, Ramírez (1992) encuentra que Zacapu es uno de sus "bastiones" en el estado de Michoacán. A pesar de la estructura jerárquica y autoritaria del Sindicato Nacional, las expresiones regionales son diversas. En Zacapu es un movimiento que goza de aceptación entre sectores sociales que 
no pertenecen al magisterio; por ejemplo, cuenta con nexos entre las corporaciones campesinas locales. Más recientemente, mediante sus contactos en Morelia lograron que la UPN con sede en Morelia impartiera en Zacapu una Maestría en diseño curricular con la finalidad de contar con un mayor número de posgraduados entre su planta docente.

Luego de seis años de trabajo académico, dada su capacidad y experiencia en la administración en todas las áreas de todo tipo de empresas tuvieron la posibilidad de apoyar con asesoría especializada a un partido de oposición que triunfó en las elecciones municipales (1990). Se trata de un partido nacional que en varios lugares de Michoacán ha logrado en años recientes recuperar un imaginario de comunalidad y autonomía local cuyos orígenes se encuentran en la ideología post-revolucionaria. Este imaginario ha tenido efectos concretos en algunas localidades según su identidad cultural y política derivada de procesos históricos particulares. Evoca un proyecto en pro de la construcción de una comunidad nacional imaginada en el que el centro de cohesión es la consecución de la justicia social. En varias regiones de Michoacán este partido ha logrado apelar de forma efectiva las identidades que surgieron con el cambio de estructuras de representación nacional post-revolucionarias y que tuvieron efectos en la categorización de amplios sectores de la población: ejidatarios y obreros (Aitken 1996: 28).

La administración municipal 1990-92 de Zacapu fue la primera en que dicho partido gobernó el municipio. Fue singular además por su lucha a favor del fortalecimiento del municipio libre, logró que el impuesto predial recaudado permaneciera en el municipio, experimentó con una especie de "asambleas populares" y evitó el movimiento de una parte de los impuestos recaudados de las tenencias hacia la cabecera municipal (Ramírez 1996:154 ss.). ${ }^{18}$ En esos años, el CUVZ aportó el diseño de procedimientos y sistemas de la administración municipal. El profesor que ocupó el cargo de presidente del ayuntamiento y su secretario reconocieron su necesidad de asesoría para manejar la administración municipal y solicitaron el

${ }^{18}$ Entrevistas con ambos profesores. 
auxilio de "la universidad". Estos vínculos concretos entre la escuela y una administración municipal cobran mayor sentido aún cuando se profundiza en la historia personal de los personajes involucrados. En el caso del expresidente municipal, destaca su colaboración en la fundación de una secundaria en una localidad rural, en un movimiento campesino a favor del alza del precio de la alfalfa y en la movilización en contra de la toma de posesión del gobernador de Michoacán en 1989 contra el cual votó principalmente el sector rural del municipio. Egresó de una normal rural y en algún momento se incorporó al Partido Comunista. Con su trayectoria de vida corrobora a Latapí, quien afirma que "del proyecto socialista...habían de quedar...algunas reafirmaciones y valores importantes que perdurarían...sobre todo en la tradición del normalismo magisterial" (1998: 28). Es un testimonio de los efectos que tuvieron, en este caso en la región de Zacapu, instituciones post-revolucionarias como la Escuela "La Huerta" cercana a Morelia, las varias escuelas y las pocas normales rurales (Vaughan 1997), o las escuelas industriales de Pátzcuaro (que albergó principalmente jóvenes indígenas) y Morelia en las que "comenzó a cultivarse la conciencia cooperativista entre 600 alumnos" (Ginzberg 1999: 211).

\section{Tradiciones e innovaciones: Ceremonialidad y discursos públicos}

En el análisis de las prácticas ceremoniosas y actos públicos en los que participa cada escuela, aparecen algunas de las estrategias de naturalización de una forma particular de entender el mundo social. Son situaciones concretas en las que las ideologías, entendidas como valores o selecciones culturales usados con fines políticos, cobran efectividad. Aunque tal efectividad depende también de la congruencia entre lo que la escuela ofrece y las tradiciones a las que los promotores de las escuelas apelan al intentar comunicarse con actores diversos de cada región.

La Universidad de Zamora realiza y asiste casi exclusivamente a eventos dentro del ámbito estrictamente académico y oficial como la sesión del Consejo regional de ciencia y tecnología de Zamora, la marcha oficial de centros educativos el día 20 noviembre que se 
conmemora la Revolución mexicana, el acto académico de "investidura de egresados" al terminar cada ciclo escolar anual, y realiza jornadas académicas de cada una de las licenciaturas. Es relevante notar que estas últimas no están dirigidas a un público en lo mínimo especializado. ¡A los estudiantes de psicología, ciencias de la comunicación, trabajo social y derecho los expositores generalmente los tratan como gente lega! Esto confirma una orientación a formar primero personas íntegras y en segundo lugar profesionistas especializados (al menos al nivel que requiere un licenciado).$^{19}$

Algunos de los símbolos centrales del acto de investidura de egresados son una apropiación contemporánea de los símbolos de primeras universidades. ${ }^{20}$ Entre estos símbolos están: el birrete y la toga, pasar del lado izquierdo al derecho la borla del birrete y el abrazo por parte del rector a cada egresado para marcar la transición de alumno a egresado, el título mismo de rector, entre otros. El objetivo es mostrar una especie de "consanguinidad" con una esencia humanista que, metafóricamente a través del uso legítimo de los símbolos, según los directivos, compartiría la Universidad de Zamora con aquellas primeras universidades. Esta fraternidad se refuerza con un paralelismo que compara un elemento seleccionado del "contexto" de la época de aquellas escuelas: aquellas primeras universidades surgieron en ciudades pequeñas como Zamora. Al mismo tiempo, se omiten cambios esenciales en la organización social como el hecho de que el reconocimiento de algunas de estas universidades era dado por el Papa. Es decir, se genera una tradición inventada con fines estratégicos para lograr el apoyo a la Universidad de Zamora, humanista como las originales.

Los elementos simbólicos presentes en este mismo acto, creados a partir del interpretante son: un círculo formado por el presidium y

19 En comentarios reflexivos pero no motivados por el investigador, los egresados y alumnos más apegados al proyecto se dan cuenta de tal jerarquización de prioridades. Por ejemplo, en las jornadas la mayoría de los ponentes improvisa una participación oral, son personas con experiencia laboral que relatan sus vivencias en un lenguaje cotidiano, o especialistas dedicados a dar conferencias para "transformar a las personas".

${ }^{20}$ Estas líneas fueron redactadas a partir de la observación en vivo, grabación y observación repetida de los actos de egresados de dos generaciones en 2001 y 2002. 
los futuros egresados y la ausencia de un estrado o mesa que divida al presidium de los egresados, todo en señal de cercanía personal y comunión, la emisión de una frase poética diseñada para cada uno de los alumnos que egresan según el conocimiento personal que el rector tiene de ellos y el mismo saludo "persona a persona" con el que se marca el estatus de egresado sin usar ninguna entrega simbólica de algún papel -el papel como una "cosa" opuesta, diferente y menos importante que las personas. Porque en la Universidad de Zamora, también llamada "universitaria tarea común zamorana", el objetivo principal según sus Criterios estatuidos es amar y crecer, ser contagiadores de humanidad, del principio de valorar a cada persona sobre las cosas. Tal que su lema es "Unusquisque homo ut scopus", "Cada hombre como meta". Por los comentarios espontáneos de los alumnos que asisten y escuchan al rector me he dado cuenta de que algunos realmente reflexionan y se identifican con su discurso. En pláticas informales comentó una alumna, quien ha dado pláticas de Biblia en la plaza central como parte de las actividades de la Universidad: "la gente dice que 'está muy influida por Faustino' pero la verdad es que las experiencias que he tenido son compatibles con las enseñanzas de la Universidad". ${ }^{21}$

A pesar de que en los discursos públicos se apela repetida pero tibiamente a una "comunidad" zamorana, no se ha podido evocar una comunidad zamorana de manera efectiva entre la mayoría de los alumnos y padres de familia. Esto es así en parte porque entre los "usuarios" de esta universidad privada predomina la idea de que se trata de una escuela particular, como las hay muchas en esta ciudad, en la que se paga por un servicio. $Y$ también porque los marcos de interacción y símbolos principales en la ciudad no refieren a una "comunidad" sino a la familia y a individuos inmersos en familias; ${ }^{22}$ o a ciudadanos con capacidades diferentes y mismos los derechos sin

${ }^{21}$ La joven estudiante se formó en una primaria católica y ha asistido a grupos para la formación de laicos católicos.

22 Principios difundidos por la iglesia, el partido político predominante en los últimos lustros, y por las mismas familias que constituyen empresas familiares bajo el tutelaje del padre (Boehm, 2001). 
aludir a sus relaciones asimétricas; ${ }^{23}$ y también refieren al libre mercado en el que compiten y cotidianamente trabajan rancheros y ejidatarios transformados en pequeños empresarios y comerciantes. ${ }^{24}$ Por otro lado, el marco de comunidad que predomina localmente en todo caso es el de una comunidad universal: la del catolicismo ecuménico. Si acaso algunos de los miembros de la asociación de apoyo Pro-Universidad de Zamora declaran explícitamente los beneficios de un proyecto común de sociedad zamorana en el que la Universidad tendría un papel importante.

El Centro Universitario del Valle de Zacapu, además de asistir al acto oficial en el que participan todas las escuelas (el desfile del veinte de noviembre) ha asistido como institución al II Congreso Nacional Indígena celebrado en la comunidad de Nurio, municipio de Paracho al suroeste de Zacapu que contó con la presencia de representantes del Ejército Zapatista de Liberación Nacional; a la entrega de un ante-proyecto de Ley indígena para el Estado de Michoacán al gobernador Lázaro Cárdenas realizado en abril de 2002 en una localidad de la cañada de los once pueblos purépechas, Tacuro, ubicada al oriente; a una ceremonia inventada hace veinte años, el Año Nuevo Purépecha, impulsada por profesionistas con vínculos políticos diversos con la finalidad de fortalecer una identidad indígena regional que trascienda las divisiones entre comunidades purépechas por pleitos por la tierra, este último acto realizado en Cherán al sur de Zacapu en febrero de 2001. El carácter y los personajes involucrados en estos eventos públicos muestran la orientación del proyecto educativo del CUVZ. El ámbito espacial y el tipo de localidades en las que se realizaron estos actos también indican que el CUVZ se encuentra inserto en un tejido de ritualidad regional por el que se comunican diversas comunidades indígenas y que se ha

${ }^{23}$ En las entrevistas sobre la diversificación de las ofertas de educación superior en Zamora, los entrevistados destacaban lo "bueno" de la amplitud de opciones, pero todos omitieron que la oferta estaba económicamente jerarquizada.

${ }^{24} \mathrm{El}$ ethos ranchero implica individualismo, logros personales independientes del gobierno nacional, legitimidad de la autoridad eclesiástica (Barragán, 1990). 
sostenido como una selección cultural relevante (tradición sedimentada). ${ }^{25}$

Durante el acto de egresados que se celebra al final de cada ciclo escolar se muestran algunos símbolos que están pensados de forma intencional para intentar la incorporación de ciertos valores en los jóvenes a través de esta experiencia solemne que es el acto de egreso y que tiene un significado emocional fuerte para ellos. La Bandera de la nación purépecha, surgida en las recientes luchas por los derechos indígenas a inicios de los ochenta, al lado de la Bandera Nacional, es realmente usada como bandera y no simplemente como estandarte puesto que se le presenta en la escolta durante el acto de honores a la Nacional. A uno de los actos asistieron representantes de las comunidades indígenas de Pátzcuaro, vestidos con la indumentaria considerada tradicional y portada de manera digna. En algún momento de la ceremonia los alumnos leyeron frases de lealtad y pertenencia a una comunidad o a un pasado indígena. Como símbolo del trabajo profesional que inicia los familiares le entregan al futuro egresado un portafolio y le dan un empujón que lo encamina a la carrera laboral-profesional. Por su parte, el alumno hace una muestra de la futura retribución al sacrificio que ha realizado la familia para sostener sus estudios mediante la entrega de algunas monedas. Buscando fortalecer la valorización del acceso a al educación superior como un derecho y no como una mercancía, el padrino de la generación que egresaba recomendó a los jóvenes dar clases en universidades públicas, "mientras más pobre [la escuela] mejor", como una forma de reciprocidad por lo recibido en el CUVZ

\section{Los interpretantes}

En el nivel discursivo los intentos por dar un orden al mundo simbólico humano, por lograr que ciertos vínculos entre signos se vuelvan convencionales, son más precisos y consistentes en el caso de

\footnotetext{
${ }^{25}$ Esto no elimina que existan pleitos añejos, principalmente por tierras y bosques comunales, entre ellas.
} 
la Universidad de Zamora; y es que el rector, a mi parecer muy adecuadamente, se auto-define como un pensador y ha dedicado sus últimos años a escribir lo que sistemáticamente ha estado tratando de difundir con la Universidad de Zamora. ${ }^{26} \mathrm{Ha}$ acuñado el concepto de "serse": alcanzar, mediante el conocimiento propio y el amor, la estatura personal, de cada ser en tanto que ser único e irrepetible, definida desde su creación por Dios, el Dios del amor posible por el misterio de la trinidad que le faculta para poder amar al no un ser solitario. De ahí que al ser el hombre creado a su imagen y semejanza pueda ser capaz de desarrollar un amor projimal. Por este camino quedan ineludiblemente ligados la integridad personal y el bien social. De acuerdo con el interpretante, una "sociedad sana" es aquella en la que sus miembros asumen responsabilidades, y primero que todo la responsabilidad personal de crecer y amar (serse). En palabras del propio fundador y rector ideológico del proyecto: "Amar es parte integrante de la naturaleza humana...Quien vive conforme a su naturaleza humana personal, crece y ama, al unísono". En este cuadro, los profesionistas dan testimonio con su vida del vivir con rectitud, una vida que al asumir la responsabilidad de serse desemboca en el beneficio de la sociedad (con una lógica y justa remuneración por su trabajo). De esta forma profesan y son los legítimos rectores rectos de la sociedad.

En el CUVZ existen elementos que indican una visión del espacio social regional y nacional penetrados por las fuerzas del mercado políticamente dirigido. Localmente se impulsa la solidaridad entre los de menos recursos económicos, incluidos los pueblos indígenas. Se argumenta a favor de una autoridad civil que favorezca a las mayorías y busque la justicia social. Una organización social en la que el Estado sea realmente el estado benefactor que nunca ha existido en México. $Y$ ante los cambios en las formas de producción industrial se procura dotar de recursos a los jóvenes zacapenses para que puedan responder de manera pragmática e inmediata a la precariedad y falta de empleos, mediante la preparación en la

${ }^{26}$ Esto no impide que existan contradicciones entre el discurso y las prácticas cotidianas reales en diversos ámbitos institucionales. 
formación de microempresas y en el ascenso laboral dentro de grandes empresas. ${ }^{27}$ En general se busca la defensa del "Pueblo" frente a un futuro bi-polar que separa a los muy ricos de los muy pobres. Tal como reza el lema del CUVZ: "La Universidad al Pueblo y el Pueblo a la Universidad", tomado de un mural de Siqueiros. Parte de esta imagen de sociedad se muestra en el siguiente fragmento del discurso de la directora durante el acto de egreso:

El problema está en el neoliberalismo, el neoliberalismo que por definición busca la protección a los grandes consorcios, al capital internacional, la protección al poder económico, sin importar el futuro de los pueblos. En esta situación nosotros tenemos que permanecer de pie, para que nuestra América deje de ser un continente pobre y dependiente. Ahora, la lucha es de todo el poder económico a nivel mundial contra los proletarios de todo el mundo también. Es pues, ahora indispensable la globalización de los pobres. Hemos encontrado compañeros, pobres, en el Canadá, en Estados Unidos, que nos vienen a apoyar con conferencias, que nos vienen a apoyar también con las nuevas ideas.

\section{Conclusiones}

Los interpretantes que orientan la concreción de símbolos, prácticas y discursos particulares se alimentan de tradiciones culturales que tienen una profundidad histórica distinta y contrastante. De manera que las innovaciones en el significado de los signos están orientadas por relaciones concretas, por instituciones y formas particulares de interiorización de normas y valores en las personas pertenecientes a diferentes grupos sociales regionales. Las universidades locales presentadas, en tanto que marcos de interacción entre múltiples actores, son parte de este complejo proceso de generación del sentido cultural de los signos.

\footnotetext{
${ }^{27}$ Aunque no he desarrollado la información sobre prácticas docentes y su efectividad, por el directorio de egresados y las pláticas con algunos de ellos calculo que un alto porcentaje trabaja en su área profesional.
} 
Otros marcos de interacción que también suponen interacción desigual entre grupos culturales y que podrían ser analizados desde esta misma perspectiva son: los museos locales, los diversos escenarios con partidos políticos, el "pueblo indígena", y los ya clásicos en la antropología mexicana: nación, comunidad, ejido, en los que tienen lugar luchas por las representaciones y por las articulaciones entre grupos culturales. La construcción cultural de la moral se cristaliza transitoriamente en valores y símbolos como si fueran inmóviles y compartidos por una colectividad que en realidad está internamente diferenciada y contiene intereses encontrados. La construcción del "bien común" se realiza en parte mediante tentativas de convenciones impulsadas por actores en posiciones concretas del espacio social (Roth 1997).

En Zamora destaca la construcción de un discurso que retoma principios de lo que recientemente se ha ido estableciendo como "políticamente correcto": Tolerancia a la diversidad cultural y política, pero omitiendo que las diferentes capacidades restringirán a los que son diferentes. Tal que un fundador de FESVAZAC simplemente comenta ante la labor cultural y educativa de los Legionarios: "Me da gusto que se hagan esas obras, sea quien sea el que las realice. Es mi pueblo, qué más puedo decir" (Proceso, loc.cit.). En entrevista con otro de los promotores de la UNIVA comentó sobre "lo bueno" de que haya variedad en la oferta educativa en Zamora, pasando por alto las diferencias en cuotas y acceso a tal diversidad y la desigual capacidad de instaurar las instituciones que tienen los diversos grupos culturales. Similarmente, un participante de Pro-Universidad señala los beneficios de tener un proyecto "común" para todos los zamoranos, michoacanos y mexicanos pero no dice quién y cómo definirá los lineamientos de tal proyecto. Con una red más restringida de relaciones, en el CUVZ se destaca la desigualdad y la pobreza que imperan en el país, e intenta formar lazos de comunidad seleccionando la condición original de pobre e indígena de los jóvenes que asisten a la escuela y de sus familiares. ${ }^{28}$

\footnotetext{
${ }^{28}$ Dado que se trata de una investigación en curso, la exploración de las redes relacionadas con cada escuela se encuentra todavía inacabada.
} 
He querido subrayar el contraste en las posibilidades simbólicas y materiales para sostener proyectos educativos y culturales muy diferentes en cada ciudad. Reconozco que este artículo puede ser un tanto impresionista por no detallar los campos de relaciones sociales históricamente conformados en los que han surgido estas instituciones dado que las referencias a fuentes historiográficas han sido mínimas y no sistemáticas. Se corre el riesgo de dejar la impresión de que Zamora es católica, "criolla" y anti-agrarista frente a Zacapu agrarista e indígena. Pero el conjunto de procesos de regionalidad es complejo en todo el estado de Michoacán y el objetivo de este artículo era precisar con algo de detalle algunos de los mecanismos de cómo funcionan las universidades locales en tanto que marcos de interacción complejos, dentro de espacios sociales regionales. En el proceso de institucionalización de estas escuelas de educación superior se aprecia la innovación y la recuperación de articulaciones culturales previas. En este proceso están involucradas redes de relaciones, vínculos institucionales (instituciones formadoras de personas como entes sociales), jerarquizaciones de grupos regionales y construcción de articulaciones culturales (selecciones jerarquizadas que privilegian símbolos de los grupos en el poder) muy concretos.

Espero que la etnografía de estos dos casos sirva como un punto para el debate y como referencia para el diálogo entre filósofos y antropólogos sobre el tema de la producción cultural de sentido y sobre las formas en que las instituciones educativas pueden ser estudiadas como parte integrante de regiones culturales internamente diferenciadas.

\section{Referencias}

Aitken, Robert, "Neoliberalism and identity: redefining state and society in Mexico", Aitken et al (eds.), Dismantling the Mexican State?, Nueva York, St. Martin Press, 1996.

Almada, Rossana, El vestido azul de la sultana. La construcción del PAN en Zamora, 1940-1995, Zamora, El Colegio de Michoacán, 2001. 
ANUIES, Estadisticas de Educación Superior, 2000, www.anuies.mx, 20 febrero, 2002.

Bakhtin, M. Le marxisme et la philosophie du langage, Paris, Ed. Minuit, 1987.

Barragán, Esteban, "Identidad ranchera. Apreciaciones desde la sierra sur 'jalmichiana' en el occidente de México", Relaciones 43, 1990, 75106.

Boehm, Brigitte, "La familia oligárquica y su sistema de parentesco: Un modelo de percepción y una propuesta de organización regional en el centro-occidente de México", Ms., febrero 1998, 20 pp.

Calvin, William y Derek Bickerton, Lingua ex Machina, España, Gedisa, 2001.

Ceballos Ramírez, Manuel, El catolicismo social: Un tercero en discordia, México, El Colegio de México, 1991.

Clifford, James y George Marcus (eds.), Writing culture: the poetics and politics of ethnography, Berkely, Universidad de California, 1986.

De Amorim, Sertório y Silva Neto, "As críticas de Vico e Horkheimer ao racionalismo cartesiano: A negação da razão naturalista em nome da filosofia humanista", Educação e Filosofia 15, 29, 175-198, 2001.

Deacon, Terrence, The Symbolic Species, New York, Norton, 1997.

Friedrich, Paul, Revuelta agraria en una aldea mexicana, México, F.C.E., 1981.

Geertz, Clifford, La interpretación de las culturas, Gedisa, México, 1987.

Ginzberg, Eitan, Lázaro Cárdenas: Gobernador de Michoacán (19281932), Zamora, El Colegio de Michoacán, UMSNH, 1999. 
Harvey, David, Justice, Nature $\mathcal{E}$ the geography of Difference, Oxford, Blackwell, 1999.

Hernández, Miguel, Dilemas postconciliares, Zamora, El Colegio de Michoacán, 1999.

INEGI, XII Censo general de población y vivienda 2000, México, INEGI, 2001.

Kent, Rollin y Rosalba Ramírez, "La educación superior en el umbral del siglo XXI", Latapí, Pablo (coord.), Un siglo de Educación en México II, México, F.C.E., 298-324, 1998.

Latapí, Pablo, "Un siglo de educación nacional" en Latapí, op. cit., 1998, 21-42.

Lomnitz, Claudio, Las salidas del laberinto, México, Joaquín MortizPlaneta, 1995.

Mead, George H., Espíritu, persona y sociedad, México, Paidós, 1990.

Mendoza Rojas, Javier, "La educación superior privada", en Latapí, op.cit., 1998, 325-354.

Mintz, Sidney y Eric Wolf, "Reply to Michael Taussig", Critique of Anthropology, Vol. IX, No. 1: 25-31, 1989.

Mummert, Gail, Tierra que pica. Transformación social de un valle agrícola michoacano en la época post-reforma agraria, Zamora, El Colegio de Michoacán, 1994.

Nugent, Stephen, "The «Peripherial Situation»", Annual Review of Anthropology 17, 79-98, 1988.

Purnell, Jennie, Popular movements and state formation in revolutionary México: The agrarist and cristeros of Michoacán, Durham, Duke University Press, 1999. 
Educação e Filosofia, 17 (33) 139-169, jan./jun. 2003

Ramírez, Luis, "Movimiento social, sociedad civil y legitimidad: el Movimiento Democrático de los Trabajadores de la Educación en Zacapu", en Zendejas, S. (ed.), Estudios michoacanos IV, Zamora, El Colegio de Michoacán, 63-90, 1992.

Ramírez, Luis, Dibujo de sol con nubes o historia de una utopía nonata, Tesis, México, El Colegio de Michoacán, 1996.

Roseberry, William, Anthropologies and histories, New Brunswick, Rutgers University Press, 1989.

Roseberry, William, "Multiculturalism and the Challenge of Anthropology", Social Research, V.59, p.841, 1992.

Roth, Andrew, "Región y cultura popular. Notas sobre moralidad, interés y objetivación de 'comunidad' en la zona interétnica del nortecentro de Michoacán", Relaciones 72, Vol. xviII, 1997.

Sayer, Andrew, "Postmodernist Thought in Geography: A realist view", Antipode, 25, 4, 1993, p. 320-344.

Smith, Gavin, Confronting the present, Berg, Oxford, 1999.

Tapia Santamaría, Jesús, "Rituales marianos e implantación de dominios", México en fiesta, Zamora, El Colegio de Michoacán, Secretaría de Turismo, México, 347-390, 1998.

Taussig, Michael, "History as commodity in some recent American (anthropological) literature", Critique of Anthropology, Vol. IX, No. 1: 7-23, 1989.

Vaughan, Mary Kay, Cultural Politics in Revolution. Teachers, peasants, and schools in Mexico, 1930-1940, Tucson, Prensa de la Universidad de Arizona, 1997. 
Verduzco, Gustavo, Una ciudad agrícola: Zamora. Del Porfiriato a la agricultura de exportación, México, El Colegio de México, El Colegio de Michoacán, 1992.

Williams, Raymond, Marxismo y literatura, España, Península, 1980.

Wolf, Eric, Envisioning Power, Berkeley, University of California Press, 1999.

Fuentes hemerográficas:

Guia. Seminario regional independiente, Zamora, Mich.

Revista Proceso, México, D.F. 